\title{
Stem Cells Regenerative Properties on New Rat Spinal Fusion Model
}

\author{
K. KLÍMA ${ }^{1}$, V. VANĚČEK ${ }^{2}$, A. KOHOUT ${ }^{3}$, O. JIROUŠEK ${ }^{4}$, R. FOLTÁN $^{1}$, J. ŠTULÍK $^{5}$, \\ V. MACHOŇ ${ }^{1}$, G. PAVLÍKOVÁ ${ }^{1}$, P. JENDELOVÁ ${ }^{2,6}$, E. SYKOVÁ ${ }^{2}$, J. ŠEDÝ \\ ${ }^{1}$ Department of Oral and Maxillofacial Surgery, General University Hospital, Prague, Czech \\ Republic, ${ }^{2}$ Institute of Experimental Medicine, Academy of Sciences of the Czech Republic, \\ Prague, Czech Republic, ${ }^{3}$ Fingerland's Department of Pathology, Charles University Medical \\ Faculty and Teaching Hospital in Hradec Králové, Czech Republic, ${ }^{4}$ Institute of Theoretical and \\ Applied Mechanics, Academy of Sciences of the Czech Republic, Prague, Czech Republic, ${ }^{5}$ Center \\ for Spinal Surgery, University Hospital Motol, Prague, Czech Republic, ${ }^{6}$ Second Faculty of \\ Medicine, Charles University, Prague, Czech Republic, ${ }^{7}$ Institute of Physiology, Academy of \\ Sciences of the Czech Republic, Prague, Czech Republic
}

Received December 27, 2013

Accepted July 29, 2014

On-line September 5, 2014

\section{Summary}

Stem cells biology is one of the most frequent topic of physiological research of today. Spinal fusion represents common bone biology challenge. It is the indicator of osteoinduction and new bone formation on ectopic model. The purpose of this study was to establish a simple model of spinal fusion based on a rat model including verification of the possible use of titanium microplates with hydroxyapatite scaffold combined with human bone marrow-derived mesenchymal stem cells (MSCs). Spinous processes of two adjacent vertebrae were fixed in 15 Wistar rats. The space between bony vertebral arches and spinous processes was either filled with augmentation material only and covered with a resorbable collagen membrane (Group 1), or filled with augmentation material loaded with $5 \times 10^{6} \mathrm{MSCs}$ and covered with a resorbable collagen membrane (Group 2). The rats were sacrificed 8 weeks after the surgery. Histology, histomorphometry and micro-CT were performed. The new model of interspinous fusion was safe, easy, inexpensive, with zero mortality. We did not detect any substantial pathological changes or tumor formation after graft implantation. We observed a nonsignificant effect on the formation of new bone tissue between Group 1 and Group 2. In the group with MSCs (Group 2) we described minor inflamatory response which indicates the imunomodulational and antiinflamatory role of MSCs. In conclusion, this new model proved to be easy to use in small animals like rats.

\section{Key words}

Animal model $\bullet$ Rat $\bullet$ MSCs $\bullet$ Bone graft substitute $\bullet$ Spinal fusion

\section{Corresponding author}

J. Šedý, Institute of Physiology, Academy of Sciences of the Czech Republic, Vídeňská 1083, Prague 4, 142 20, Czech Republic. Fax: +420-241062488. E-mail: jirisedy@hotmail.com

\section{Introduction}

In the bone biology one of the most common approach is based on stem cells. The concept of bone tissue engineering combines allogenic biomaterials with osteoprogenitor cells and growth factors. In fracture models or calvarian defect models, the research aim is to recreate the original bone anatomy. Spinal fusion models are unique. In spinal fusion models, the aim is to induce formation of osseous mass that bridges vertebral segments to stabilize the spinal column by removing intervertebral articulations and positioning the segments in appropriate, mechanically advantageous alignment (Khana and Laneb 2004).

Calcium-based bone materials are used because of their similarity to the mineral phase of bone, their osteoconductivity and good biocompatibility (Wang et al. 2011). However, for the successful repair of large bone 
defects, the graft material should also have osteoinductive or even osteogenic properties. In order to enhance bone formation within the implanted synthetic grafts, various growth factors such as bone morphogenic protein (BMP) or tumor necrosis factor beta (TGF-beta) have been used in combination with the synthetic bone material (Niu et al. 2009). Additionally, methods of tissue engineering using mesenchymal stem cells (MSCs) have been studied as a potential therapeutic tool for bone tissue regeneration (Griffin et al. 2011). The osteogenic and immunological properties of MSCs, together with the possibility to relatively easy to obtain, cultivate and produce these cells in large amounts, represent advantages over other types of cells. Combined with hydroxyapatite scaffolds, they were shown to enhance the osteoinductivity of calciumbased scaffolds and to promote bone healing in various experimental bone defects including long bone fractures (Choi et al. 2011), spinal fusion (Huang et al. 2011) and craniofacial defects (Miura et al. 2006). However, the specific biomechanical properties of vertebrae do not allow generalizing the results from other types of bones to those of vertebral body defects treated with a tissue engineered graft. In response to this, animal models of vertebral body defects in rats or sheep were recently used to study the effect of bone replacement materials (Liang et al. 2010, Zhu et al. 2011). In particular, the possibility of using autologous human MSCs to improve bone healing without the necessity for long precultivation of the cells in a scaffold prior to transplantation might significantly simplify the research in bone biology.

In order to implement stem cell therapies, we have conducted a study to evaluate the safety and efficacy of a new rat model of dorsal lumbar spinal fusion stabilized with titanium miniplates with a hydroxyapatite bone scaffold combined with defined human bone marrow-derived mesenchymal stem cells.

\section{Materials and Methods}

\section{Animals}

We used 15 Wistar rats (Anlab, Charles River Laboratories, Köln, Germany) with body weights of $300-350 \mathrm{~g}$. We included only males in our study to minimize the effects of hormone levels on the variability of the healing as well as bone regeneration (Luize et al. 2008, Šedý et al. 2008). This study was performed in accordance with the European Communities Council Directive of 24 November 1986 (86/609/EEC) regarding the use of animals in research and was approved by the
Ethical Committee of the Institute of Experimental Medicine AS CR, Prague, Czech Republic. All efforts were made to minimize the number of animals used in the study.

\section{Experimental groups}

Rats were randomly divided into one of the following groups: (i) rats with spinal lumbar stabilisation with titanium microplates filled with hydroxyapatite augmentation material only (Group 1, N=5); (ii) rats with spinal lumbar stabilisation with titanium microplates filled with hydroxyapatite augmentation material combined with $5 \times 10^{6} \mathrm{MSCs}$ (Group 2, N=5).

\section{Cell isolation and cultivation}

Human MSCs were isolated from the bone marrow of healthy human donors. All procedures for MSCs preparation were performed under good manufacturing practice (GMP) conditions in Bioinova, Ltd. (Czech Republic) and approved by the State Institute for Drug Control of the Czech Republic (SUKL, Czech Republic). The mononuclear fraction containing MSCs was separated from the blood by gradient centrifugation using $25 \%$ Gelofusin (B. Braun, Melsungen, Germany) and seeded on plastic dishes at a concentration of $5-10 \times 10^{6}$ cells $/ 75 \mathrm{~cm}^{2}$. The cells were cultivated in media containing Alpha MEM Eagle without Deoxyribonucleotides, Ribonucleotides and UltraGlutamin (Lonza, Basel, Switzerland) supplemented with 5\% thrombocyte lysate (Bioinova, Prague, Czech Republic) and $10 \mu \mathrm{g} / \mathrm{ml}$ Gentamicine (Lek Pharmaceuticals, Ljublanja, Slovenia); non-adherent cells were washed out by changing the medium. When the cells reached $80 \%$ confluence, they were detached from the surface of the dishes with using $1 \mathrm{ml} / 75 \mathrm{~cm}^{2}$ of TrypLE CTS Select ${ }^{\mathrm{TM}}$ solution (Gibco, CA, USA) and expanded. Cells from the second passage were analyzed and used in further experiments. The expression of specific surface markers was assessed using fluorescentactivated cell sorting (FACS) analysis (FACSAria flow cytometer, BD Biosciences, San Diego, USA). The cells expressed CD105, CD73 and CD90 and were negative for CD45, CD34, CD14 or CD11b, CD79alpha and HLA-DR surface molecules. In order to verify the differentiation potential of the MSCs, the cells were differentiated into osteogenic, chondrogenic and adipogenic lineages using standard differentiation media. Cell viability (over 95\%) was evaluated by using trypan blue staining, and the cultures were tested for the presence of bacterial, fungal 
and mycoplasmatic contamination. The cells were frozen in aliquots in saline containing $7.5 \%$ dimethyl sulfoxide (DMSO) and $5 \%$ albumin and stored in liquid nitrogen at $-160{ }^{\circ} \mathrm{C}$ until use.

\section{Preparation of bone implants}

MSCs were thawed, centrifuged and washed three times with pre-warmed PBS to remove the residual freezing solution. A cell suspension at a concentration of $5 \times 10^{6}$ cells $/ \mathrm{ml}$ was prepared and transferred to a vial. A pre-wetted hydroxyapatite bone scaffold CEMOSTETIC® (Berkeley Advanced Biomaterials, Inc., Berkeley, USA) bone substitute $(0.02 \mathrm{~g})$ was soaked in the cell suspension, and the suspension containing the material was centrifuged at $1000 \mathrm{rpm}$. After centrifugation, the excess PBS was removed, and the content of the vial was mixed with a small sterile spatula to form a homogenous cell-material mixture and applied to the spinal fusion of the animal immediately.

\section{Surgery}

After the induction of anesthesia with $5 \%$ isoflurane in room air (flow $300 \mathrm{ml} / \mathrm{min}$ ), the animals were maintained in $2 \%$ isoflurane anesthesia (flow $300 \mathrm{ml} / \mathrm{min}$ ) via a face mask throughout the operation. Under aseptic conditions, a $2 \mathrm{~cm}$ dorsal skin incision at the L1-L3 level was made. The dorsal muscles were shifted laterally and the spinous processes were exposed. Soft tissues including periosteum were removed from the spinous processes and dorsal part of bony vertebral arches (Fig. 1A). We used titanium microplates with thickness $0.5 \mathrm{~mm}$ and titanium screws (Jeil Medical Corporation, Seoul, Corea) for spinal fusion. Spinous processes of two adjacent vertebrae were fixed (Fig. 1B). The space between bony vertebral arches and spinous processes was either filled with augmentation material only - Group 1 (Fig. 1C), and covered with a Hyprosorb resorbable collagen membrane (Hypro, Czech Republic), or filled with augmentation material loaded with $5 \times 10^{6}$ MSCs and covered with a Hyprosorb resorbable collagen membrane (Group 2). The soft tissues and skin were sutured with nonresorbable tread (Fig. 1D). Transplanted animals were immunosuppressed daily with $10 \mathrm{mg} / \mathrm{kg}$ intramuscular cyclosporine $\left(10 \mathrm{mg} / \mathrm{kg}\right.$, Sandimmun ${ }^{\circledR}$, Novartis, Basel, Switzerland), and bacterial infection was prevented by Gentamicine $\left(0.5 \mathrm{ml}\right.$, Gentamicine Lek ${ }^{\circledR}$, Lek Pharmaceuticals, Ljublanja, Slovenia). The rats were sacrificed 8 weeks after the surgery.

\section{Histological analysis}

At the end of the experiment, the animals were transcardially perfused under deep anesthesia (pentobarbital $150 \mathrm{mg} / \mathrm{kg}$ ) with $4 \%$ paraformaldehyde in $0.1 \mathrm{M}$ PBS. The vertebrae were dissected and the titanium microplates were gently removed. Dissected vertebrae were postfixed in $10 \%$ formaldehyde and further decalcified with formic acid. From each sample three transversal blocks were embedded in paraffin, cut in $4 \mu \mathrm{m}$ thick sections and stained with hematoxylin-eosin and chloroacetate esterase which represents a cytochemical staining technique to identify cells of the granulocyte lineage. Sections were examined under a light microscope and histomorphometrical analysis was performed using NIS-Elements software (Nikon Instruments, Inc., USA). The samples were examined using a spectral confocal microscope (Carl-Zeiss, Germany).

\section{Radiography}

From each group one specimen was selected for standard radiological examination. We used dental X-ray apparatus (Prostyle Intra, Planmeca Oy, Helsinki, Finland) to examine the whole specimen of fused vertebral segments and adjacent vertebra on each side.

\section{Micro-CT analysis}

From each group one specimen was selected for microtomographic analysis of its microstructure. The specimens were scanned using a previously developed setup (Jakubek et al. 2006). The specimens were irradiated using a micro-focus X-ray tube L8601-01 (Hamamatsu Photonics K.K., Japan) with $5 \mu \mathrm{m}$ emission spot, tungsten anode and divergent cone beam. For the imaging a flat panel X-ray detector C7942CA-22 (Hamamatsu Photonics K.K., Japan) with resolution $2368 \times 2240$ pixels and physical dimensions $120 \times 120 \mathrm{~mm}$ was used. For the acquisition we used 360 projections with $1^{\circ}$ increment. Maximum possible magnification was used, corresponding to source-object distance $170 \mathrm{~mm}$ and source-detector distance $500 \mathrm{~mm}$. Because the L8601-01 source produces X-ray beam with continuous energy spectrum, beam hardening correction was applied to the acquired radiographs to account for the non-uniform attenuation of the samples. The images were reconstructed using a cone-beam backprojection algorithm which has been previously proven suitable for precise imaging of trabecular microarchitecture of wholebone samples (Kytyr et al. 2011). Resolution of the 
reconstructed three-dimensional images is approximately $30 \mu \mathrm{m}^{3}$.

\section{Statistical analysis}

The values are reported as mean values \pm SEM. One-way ANOVA with a post-hoc LSD (least significant difference) test was used for the comparison among individual groups.

\section{Results}

\section{Experimental model}

The spinal fusion model proved to be safe, easy, inexpensive, and with zero mortality. We used titanium microplates which are used in human medicine. The dorsal muscles were shifted laterally and the spinous processes were exposed and all soft tissues including periosteum were removed (Fig. 1A). With water cooling we drilled one hole to spinous process and we fixed the microplate on it by micro-screw. Another hole was drilled to adjacent spinous process (Fig. 1B). We controled the stability of fixation manually. To the oposite side of spinal fusion the hydroxyapatite scaffold either without or with MSCs was filled (Fig. 1C). To protect the fibrous invasion into the scaffold, we covered it by resorbable collagen membrane (Fig. 1D). The membrane was fixed by first suture layer of paravertebral muscles (Fig. 1D). The layout of our model is depicted in Figure 1E.

\section{Histological examination}

In both groups (MSCs + hydroxyapatite and hydroxyapatite alone) augmentation material had appearance of clusters of tiny birefringent granules. In the group with hydroxyapatite only this material was often surrounded by foreign body multinucleated giant cells (Fig. 2A). In the vicinity of the material there was a dense collagenous connective tissue similar to scar tissue (probably consequence of operation trauma). On the periphery (and rarely in the centre) of implant area foci of new bone formation were observed. In the group with MSCs (Group 2) newly formed bone was better integrated into the surrounding bone tissue. The newly formed bone was usually of wowen type but lamellar bone was present as well (Fig. 2B). The small clusters of augmentation material were sometimes completely surrounded by newly formed bone (Fig. 2C). Trabeculae of new bone showed often rims of active osteoblasts and scattered osteoclasts as a result of active remodeling process. In the connective tissue among granules of augmentation material, many small thin-walled blood vessels were present. In Group 2 newly formed bone was better integrated into the surrounding bone tissue (Figs 2D, 3A). Moreover, new bone was more often of lamellar quality (Fig. 3B). In this group we marked absence of inflammatory infiltration (Fig. 3C). In contrast, in some cases where hydroxyapatite alone was implanted (Group 1) we observed granular augmentation material and marked mixed inflammatory infiltration containing numerous neutrophils and macrophages forming occasional giant cells (Fig. 3D). The chloracetatesterase staining verified minor inflammatory reaction in Group 2 with only scattered neutrophils (Fig. 3E), compared to Group 1 where granular augmentation material and marked mixed inflammatory infiltration containing numerous neutrophils, macrophages and giant cells were observed (Fig. 3F).
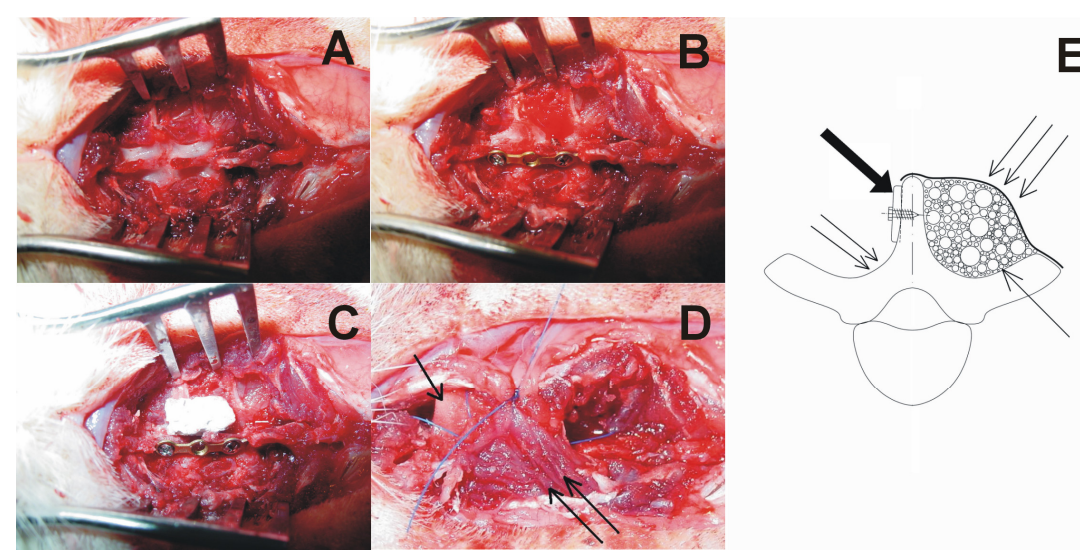

Fig. 1. Spinal fusion model. A. Surgical E access to spine. The dorsal muscles were shifted laterally and the spinous processes were exposed. Soft tissues incl. periosteum were removed from the spinous processes and dorsal part of bony vertebral arches. B. The fixation of spinous processes of two adjacent vertebrae by titanium microplates and screws. C. The area which was filled with augmentation material. The space between bony vertebral arches and spinous processes of one side was either filled with augmentation material only or with augmentation material loaded with MSCs. The amount of material, which was subsequently desintegrated and implanted into site (see Methods) is demonstrated.

D. Covering of the scaffold with a resorbable collagen membrane (arrow). The paravetebral muscles (double arrows) and skin were sutured with nonresorbable tread. E. Schematic drawing of the spinal fusion model. Microplate with microscrew (wide arrow), scaffold with/without MSC's (arrow), bony vertebral arches (double arrows), collagen membrane (triple arrows). 

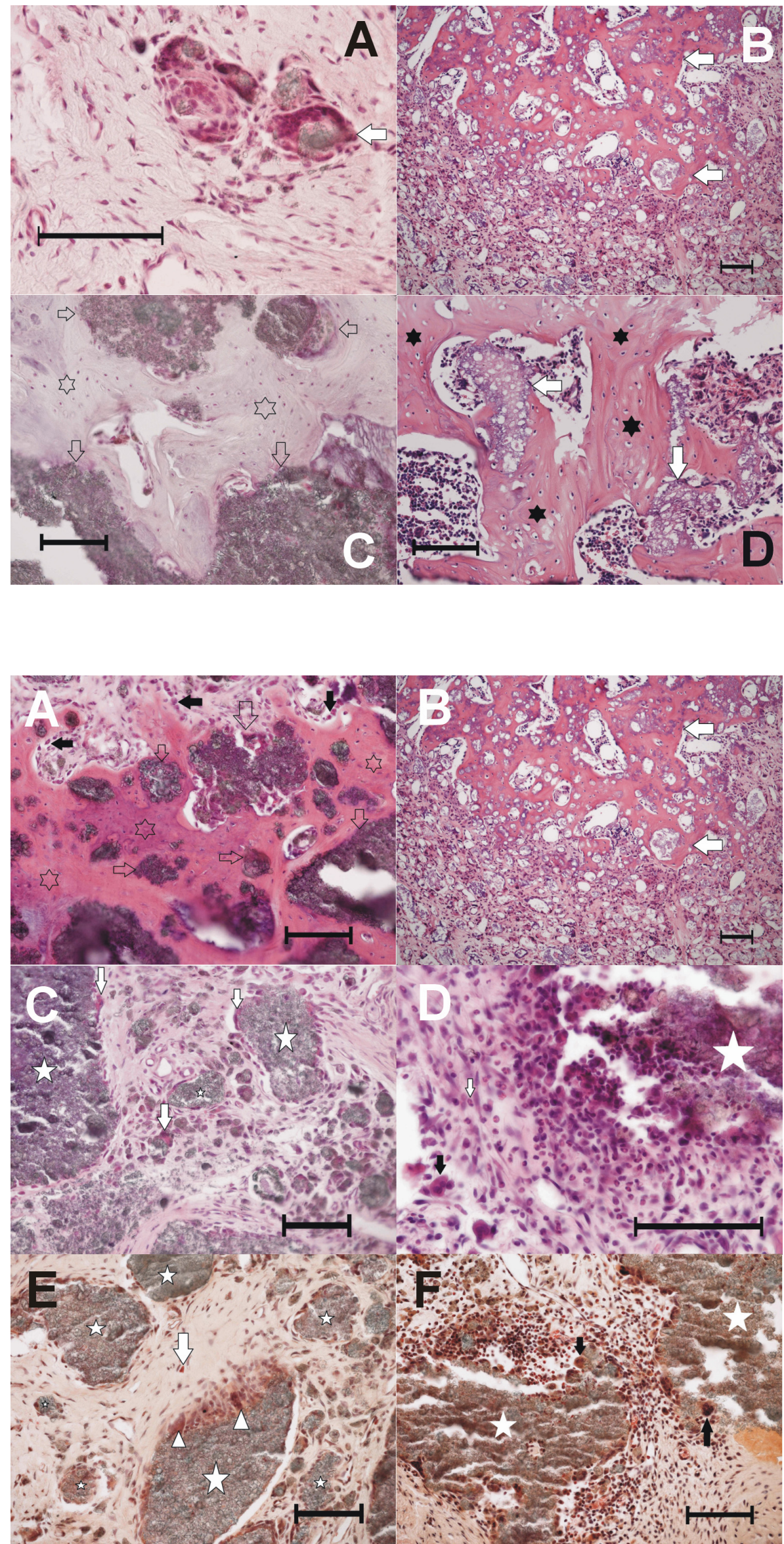

Fig. 2. Histology of augmentation material and bone. A. Foreign body giant cell reaction around augmentation material (arrow) in Group 1. B. Wowen bone formation around granules of augmentation material (arrow) in Group 1. C. Wowen and lamellar bone formation on the surface of augmentation material. Broad bony trabeculae (asterisks) with incorporated granular augmentation material (arrows) in a Group 1. D. Broad well formed trabeculae of lamellar bone (black asterisks) on the surface of augmentation material (white asterisks) in Group 2. Staining hematoxylin-eosin. Scale $=100 \mu \mathrm{m}$.

Fig. 3. Histology of augmentation material and bone. A. Broad areas of predominantly woven bone (asterisks) with incorporated granules of augmentation material (white arrows). Note rims of active osteoblasts on the trabecular surface (black arrows) in Group 2. B. Broad trabecula of lamellar bone on the surface of augmentation material (white arrows) in Group 2. C. Granular augmentation material (asterisks) surrounded by numerous giant cells (arrows) in Group 2. Note the absence of inflammatory infiltration. D. Granular augmentation material (asterisk) and marked mixed inflammatory infiltration containing numerous neutrophils (white arrow) and macrophages forming occasional giant cells (black arrow) in Group 1. E. Granular augmentation material (asterisks) surrounded by numerous giant cells (arrowheads) in Group 2. Only scattered neutrophils are present. F. Granular augmentation material (asterisks) and marked mixed inflammatory infiltration containing numerous neutrophils (bright red cytoplasm), macrophages and giant cells (black arrows) in Group 1. Staining was done with either hematoxylin-eosin $(A, B, C, D)$ or chloracetatesterase $(\mathrm{E}, \mathrm{F})$. Scale $=$ $100 \mu \mathrm{m}$. 


\section{Histomorphometry}

Quantitative analysis of the samples revealed nonsignificant differences in the volume of new bone formation $(\mathrm{p}=0.56)$ between the Group $1(28.54 \pm 6.22 \%)$ and Group $2(24.01 \pm 4.36 \%)$. The analysis of the samples revealed also nonsignificant differences $(p=0.17)$ in the percentage of residual scaffold between Group 1 (31.52 $\pm 6.96 \%$ ) and the Group 2 (42.75 \pm 4.24$)$ (Fig. 4).

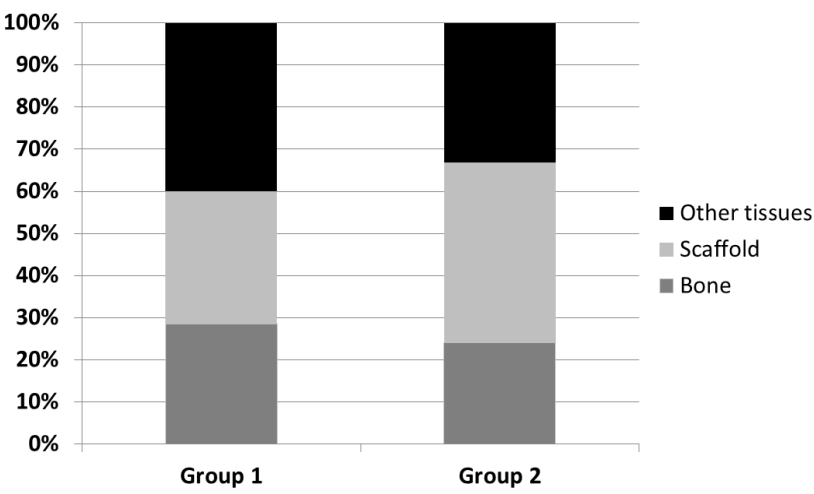

Fig. 4. Quantitative analysis of the volume of new bone formation in Group 1 vs. Group 2. Quantitative analysis of the samples revealed nonsignificant differences in the volume of new bone formation $(p=0.56)$ as well as residual scafold $(p=0.17)$ between Group 1 and Group 2. Other tissues represent all tissues which could not be recognized as a bone or scaffold, mainly fibrous tissue and vessels.

\section{Radiography}

Radiological examination on standard dental $\mathrm{X}$-ray apparatus was done without removal of plates and screws. The aim of standard radiographic examination was to discover any adverse mechanic effects of spinal fusion like screws displacement, fracture of microplates etc. We observed only small release of one screw but without dislocation out of the drilled screw hole (Fig. 5). We did not observed any titanium microplate dislocation or fracture (Fig. 5).

\section{Micro-CT imaging}

Before micro-CT, we gently removed titanium miniplates to reduce metallic artifacts on micro-CT. The location of the spinal fusion was clearly observable in axial projection (Fig. 5C). In Group 2, we observed trend towards higher bone regeneration. The residual scaffold appeared in micro-CT scans in those places, which did not come into contact with the bone. This finding suggests ossification spreading from the line of the bone on $3 \mathrm{D}$ reconstruction (Fig. 5D). This corresponds to our histological findings, in which we observed higher bone formation in contact with the bone.

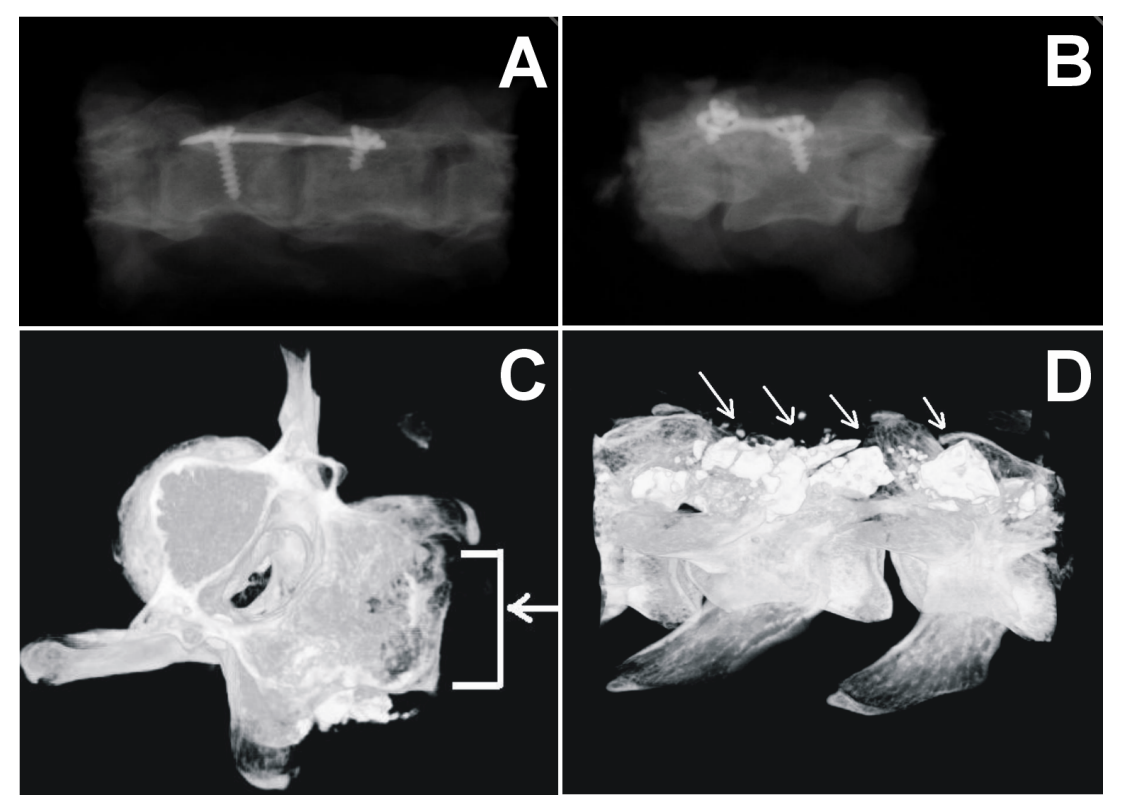

Fig. 5. Radiological $(A, B)$ and micro- $C T(C, D)$ examination of spinal fusion in Group 2. A. Fixation with correct screw position. B. Stable spinal fusion with titanium microplate and screws revealed a small dislocation of left screw without failure of the fixation. C. Axial projection of micro-CT (arrow). D. 3D reconstruction of spinal fusion with new bone formation and residual scaffold (arrows).

\section{Discussion}

In our study, we evaluated the effect of MSCs in combination with a hydroxyapatite-based scaffold on bone regeneration in a new rat spinal fusion model. Several valid and reproducible animal models of anterior and posterolateral fusion have been developed in order to assess several tissue engineered bone constructs (Khana et al. 2004). Small animals such as rats should be avoided because of their small anatomy (Muschler et al. 2010). In contrast, small animal models are now used for investigational studies because they are inexpensive and 
heal rapidly, which raises the power and number of possible experiments and shortens time to outcome (Reid et al. 2011). The results presented here show that the fixation of spinous processes was a safe, stable and easy procedure. No animal suffered a fracture of titanium microplate or loss of the screws. Throughout the experiment, subjects did not display any neurological impairment or mortality; with both groups displaying no difference in food and water consumption.

In some studies, spinal fusion does not involve fixation of the vertebrae (Nakajima et al. 2007), even though fixation, or immobility, is considered as an essential condition of bone healing. The development of bone tissue engineering led to the invention of the triangular concept, which became a standard concept involving three interconnected factors: growth factors, scaffold, and stem cells. Giannoudis et al. (2007) added to the concept an idea of "mechanical environment", i.e. the importance of mechanical stability as a key factor of bone healing, and called their improved concept the diamond concept, which involves 4 interconnected factors: osteogenic cells, growth factors, osteogenic matrix and mechanical stability (Giannoudis et al. 2007). The process used in our study to cultivate and characterize the MSCs was carried out in accordance with Good Manufacturing Practice (GMP) and approved for preclinical and clinical studies by the State Institute for Drug Control. The characteristics of the cell phenotype complied with the standards defined by the International Society For Cellular Therapy (ISCT) (Dominici et al. 2006). MSCs used in our study were cultivated and frozen under GMP conditions. Quality and stability of frozen cells has been regularly tested in certified laboratory. MSCs were sterile and viable, retained the ability to differentiate into osteo, adipo and chondro phenotype and met criteria for defining MSCs according to Dominici et al. (2006) at least one year after freezing.

In our experiments, we used cyclosporine A as an immunosuppressant. Several groups observed potentiation between cyclosporine A and the immunosuppressive effect of human MSCs in vitro (Le Blanc et al. 2004, Maccario et al. 2005). However, since the animals with an HA scaffold only also received immunosuppression, the effect observed in animals transplanted with a scaffold loaded with cells is most likely due to the presence of the cells rather than just immunosuppression. Different experimental approaches to xenogenic MSC transplantation in terms of using immunosuppressive drugs are discussed in the literature.
Tcacencu et al. (2012) implanted human MSCs seeded on a peptide hydrogel in the mandible of immunosuppressed rats (with cyclosporine A) and reported significantly better alveolar bone density and decreased osteoclast numbers at the site of the injury, which they ascribed to the immunomodulatory effect of the MSCs and their interaction with host monocytes and macrophages (Tcacencu et al. 2012). Isomoto et al. (2007) used cyclosporine with bone marrow-derived mesenchymal stem cells. The cyclosporine with use of MSCs had no effect on osteogenesis (Isomoto et al. 2007).

Our aim was to verify osteoinduction abilities of MSCs in combination with calcium based scaffold on a simple and easy to use spinal fusion model. We tried to avoid lengthy cultivation, differentiation and expansion of the cells prior to implantation. Choi et al. (2011) showed significant bone formation in a femoral defect model after the transplantation of a fibronectin-coated HA/TCP scaffold combined with 7.5 million adipose tissue-derived MSCs, but not with 0.75 million, in comparison to material alone and pointed out the cellloading density-dependent manner of bone formation. Interestingly, when they loaded the material with 75 million MSCs, they found only a minor increase in bone formation in comparison to 7.5 million MSCs (Choi et al. 2011). Minamide et al. (2005) reported that implantation of one million bone marrow cells resulted in a poor fusion rate and less mature bone formation in lumbar spinal arthrodesis, while implantation of 100 million cells induced solid union (Minamide et al. 2005). Our previous results showed significantly greater bone formation in the group transplanted with the material loaded with 5 million MSCs in comparison to the groups treated with material loaded with 0.5 million cells or a scaffold alone (Vaněček et al. 2013), suggesting that high-density cell loading is necessary to promote the osteoinductive activity of the graft. In the present study, the MSCs density was $5.0 \times 10^{6}$ cells $/ \mathrm{ml}$ which should be sufficient, as proved by the previous study (Vaněček et al. 2013). In our previous experiment, we used the same quantity of identical stem cells with the same collagenous membrane with significant bone growth in the group hydroxyapatite $/ 5.0 \times 10^{6}$ cells $/ \mathrm{ml} \mathrm{MSCs/collagen}$ membrane in a rat vertebral body defect model. Boden et al. (1999) showed that the healing environments dramatically differ between metaphyseal defect and the posterolateral spine. Our results suggest the importance of microenvironment for osteogenesis, which could be the reason of non significant new bone formation in 
Group 2. Guided bone regeneration with a barrier membrane technique is a way to prevent soft tissue invasion into bone defects (Kazakos et al. 2011). In our present study, we used bovine collagenous resorbable membrane in both groups. Micro-CT results show that resorption and new bone formation spread from the bone line, with no osteogenic centres in the scaffold. The mechanism of mesenchymal stem cells effect has not been exhaustively described, however, it has been proved that mesenchymal stem cells are capable of osteogenic differentiation. In our present study, we observed same level of bone formation in the Group 2 with MSCs. As suggested by the aforementioned studies, this could have been caused by microenvironmental effects.

In MSCs with hydroxyapatite group newly formed bone was better integrated into the surrounding bone tissue. In chloracetatesterase staining in the group with MSCs we observed only scattered neutrophils compared with the group of hydroxyapatite only where we described marked mixed inflammatory infiltration containing numerous neutrophils, macrophages and giant cells. These findings could indicate antiinflamatory effect of MSCs. The mechanisms of anti-inflammatory and immunosupressive effect of MSCs is not fully defined and understood. Atoui et al. (2012) described in their review immunomodulatory properties of MSCs: i) MSCs avoid allogeneic response, ii) MSCs are major histocompatibility complex (MHC) class I positive and MHC class II negative. The expression MHC I protects MSCs from certain natural killer (NK)-cell-mediated deletion. Lack of expression of MHC II on MSCs allows them to escape recognition by effector CD4+ $\mathrm{T}$ cells, iii) MSCs do not express Fas-ligand or costimulatory molecules such as B7-1 (CD80), B7-2 (CD86), or CD40 for effector T-cell induction, iv) MSCs suppress B-cell activation, induce suppressor T-cell formation, $v$ ) by the release of IL-4, MSCs accelerate a shift from a majority of proinflammatory Th1 cells toward an increase in the anti-inflammatory Th2 cells (Atoui et al. 2012).

We did not observe any signs of neoplasm formation. Also, no significant bone deformation or spinal cord compression was observed in the transplanted animals, suggesting the safety of the transplantation procedure.

\section{Conclusion}

Our study proved that the model of fixation of spinous processes with titanium microplates and screws is safe, easy and inexpensive. This model can be used in small animal models, which heal rapidly and thus shorten time to outcome. We observed nonsignificant new bone formation in a group with MSCs but in presence of MSCs we described minor inflamatory reaction compared to the group without MSCs. Hopefully this easy to use spinal model for small animals can bring another advantages. Our experiment involved a simple procedure of graft preparation, which might be easily reproduced.

\section{Conflict of Interest}

There is no conflict of interest.

\section{Acknowledgements}

Grant Agency of the Czech Republic GACR 304/10/0320, Grant Agency of the Ministry of Health of the Czech Republic NT13477.

\section{References}

ATOUI R, CHIU RCJ: Concise rReview: immunomodulatory properties of mesenchymal stem cells in cellular transplantation: update, controversies, and unknowns. Stem Cells Transl Med 1: 200-205, 2012.

BODEN S: Overview of the biology of lumbar spine fusion and principles for selecting a bone graft substitute. Spine 27: 26-31, 2002.

BODEN SD, MARTIN GJ, MORONE M, UGBO JL, TITUS L, HUTTON WC: The use of coralline hydroxyapatite with bone marrow, autogenous bone graft, or osteoinductive bone protein extract for posterolateral lumbar spine fusion. Spine 24: 320-327, 1999.

CHOI HJ, KIM JM, KWON E, CHE JH, LEE JI, CHO SR, KANG SK, RA JC, KANG BC: Establishment of efficacy and safety assessment of human adipose tissue-derived mesenchymal stem cells (hATMSCs) in a nude rat femoral segmental defect model. J Korean Med Sci 26: 482-491, 2011.

DOMINICI M, LE BLANC K, MUELLER I, SLAPER-CORTENBACH I, MARINI F, KRAUSE D, DEANS R, KEATING A, PROCKOP DJ, HORWITZ E: Minimal criteria for defining multipotent mesenchymal stromal cells. The International Society for Cellular Therapy position statement. Cytotherapy 8: 315-317, 2006. 
GIANNOUDIS P, EINHORN T, MARSH D: Fracture healing: the diamond concept. Injury 38: 3-6, 2007.

GRIFFIN M, IQBAL SA, BAYAT A: Exploring the application of mesenchymal stem cells in bone repair and regeneration. J Bone Joint Surg Br 93: 427-434, 2011.

HUANG JW, LIN SS, CHEN LH, LIU SJ, NIU CC, YUAN LJ, WU CC, CHEN WJ: The use of fluorescence-labeled mesenchymal stem cells in poly(lactide-co-glycolide)/hydroxyapatite/collagen hybrid graft as a bone substitute for posterolateral spinal fusion. J Trauma 70: 1495-1502, 2011.

ISOMOTO S, HATTORI K, OHGUSHI H, NAKAJIMA H, TANAKA Y, TAKAKURA Y: Rapamycin as an inhibitor of osteogenic differentiation in bone marrow-derived mesenchymal stem cells. J Orthop Sci 12: 83-88, 2007.

JAKUBEK J, HOLY T, JAKUBEK M, VAVRIK D, VYKYDAL Z: Experimental system for high resolution X-ray transmission radiography. Nucl Instrum Methods Phys Res A 563: 278-281, 2006.

KATZ JN: Lumbar spinal fusion. Surgical rates, costs, and complications. Spine 20: 78-83, 1995.

KAZAKOS K, LYRAS DN, THOMAIDIS V, AGROGIANNIS G, BOTAITIS S, DROSOS G, KOKKA A, VERETTAS D: Application of PRP gel alone or in combination with guided bone regeneration does not enhance bone healing process: An experimental study in rabbits. J Craniomaxillofac Surg 39: 49-53, 2011.

KHANA SN, LANEB JM: Spinal fusion surgery: animal models for tissue-engineered bone constructs. Biomaterials 25: 1475-1485, 2004.

KYTÝŘ D, JIROUŠEK O, DAMMER J: High resolution X-ray imaging of bone-implant interface by large area flatpanel detector. J Instrum 6: 1038-1043, 2011.

LE BLANC K, RASMUSSON I, GOTHERSTROM C, SEIDEL C, SUNDBERG B, SUNDIN M, ROSENDAHL K, TAMMIK C, RINGDEN O: Mesenchymal stem cells inhibit the expression of CD25 (interleukin-2 receptor) and CD38 on phytohaemagglutinin-activated lymphocytes. Scand J Immunol 60: 307-315, 2004.

LIANG H, WANG K, SHIMER AL, LI X, BALIAN G, SHEN FH: Use of a bioactive scaffold for the repair of bone defects in a novel reproducible vertebral body defect model. Bone 47: 197-204, 2010.

LUIZE DS, BOSCO AF, BONFANTE S, DE ALMEIDA JM: Influence of ovariectomy on healing of autogenous bone block grafts in the mandible: a histomorphometric study in an aged rat model. Int J Oral Maxillofac Implants 23: 207-214, 2008.

MACCARIO R, MORETTA A, COMETA A, MONTAGNA D, COMOLI P, LOCATELLI F, PODESTA M, FRASSONI F: Human mesenchymal stem cells and cyclosporin A exert a synergistic suppressive effect on in vitro activation of alloantigen-specific cytotoxic lymphocytes. Biol Blood Marrow Transplant 11: 1031-1032, 2005.

MINAMIDE A, YOSHIDA M, KAWAKAMI M, YAMASAKI S, KOJIMA H, HASHIZUME H, BODEN SD: The use of cultured bone marrow cells in type I collagen gel and porous hydroxyapatite for posterolateral lumbar spine fusion. Spine 30: 1134-1138, 2005.

MIURA M, MIURA Y, SONOYAMA W, YAMAZA T, GRONTHOS S, SHI S: Bone marrow-derived mesenchymal stem cells for regenerative medicine in craniofacial region. Oral Dis 12: 514-522, 2006.

MUSCHLER GF, RAUT VP, PATTERSON TE, WENKE JC, HOLLINGER JO: The design and use of animal models for translational research in bone tissue engineering and regenerative medicine. Tissue Eng Part B Rev 16: $123-145,2010$.

NAKAJIMA T, IIZUKA H, TSUTSUMI S, KAYAKABE M, TAKAGISHI K: Evaluation of posterolateral spinal fusion using mesenchymal stem cells differences with or without osteogenic differentiation. Spine 32: 24322436, 2007.

NIU X, FENG Q, WANG M, GUO X, ZHENG Q: Porous nano-HA/collagen/PLLA scaffold containing chitosan microspheres for controlled delivery of synthetic peptide derived from BMP-2. J Control Release 134: 111-117, 2009.

REID JJ, JOHNSON JS, WANG JC: Challenges to bone formation in spinal fusion. J Biomech 44: 213-220, 2011.

ŠEDÝ J, URDZIKOVÁ L, JENDELOVÁ P, SYKOVÁ E: Methods for behavioral testing of spinal cord injured rats. Neurosci Biobehav Rev 32: 550-580, 2008.

TCACENCU I, KARLSTROM E, CEDERVALL J, WENDEL M: Transplanted human bone marrow mesenchymal stem cells seeded onto peptide hydrogel decrease alveolar bone loss. Biores Open Access 1: 215-221, 2012. 
VANĚČEK V, KLÍMA K, KOHOUT A, FOLTÁN R, JIROUŠEK O, ŠEDÝ J, ŠTULÍK J, SYKOVÁ E, JENDELOVÁ P: The combination of mesenchymal stem cells and a bone scaffold in the treatment of vertebral body defects. Eur Spine J 22: 2777-2786, 2013.

WANG Z, LU B, CHEN L, CHANG J: Evaluation of an osteostimulative putty in the sheep spine. J Mater Sci Mater Med 22: 185-191, 2011.

ZHU XS, ZHANG ZM, MAO HQ, GENG DC, ZOU J, WANG GL, ZHANG ZG, WANG JH, CHEN L, YANG HL: A novel sheep vertebral bone defect model for injectable bioactive vertebral augmentation materials. $J$ Mater Sci Mater Med 22: 159-164, 2011. 